\title{
What are students thinking when we present ethics cases?: an example focusing on confidentiality and substance abuse
}

\author{
Nancy G Stevens and Thomas R McCormick University of Washington, USA
}

\begin{abstract}
Authors' abstract
As part of an ethics course, health professions students were asked to identify ethical issues and to propose resolutions before and after a class discussion of a case involving confidentiality and substance abuse. Students listed an average of 2.4 issues before and 3.6 issues after the discussion. After discussion 50 per cent of students made explicit changes in their proposed resolution. Opinions varied widely on breaching confidentiality and the responsibility for protecting the patient's health. After the discussion almost 20 per cent of the class felt it was acceptable to breach confidentiality as long as the patient was unaware. Many students identified more with the health care provider than with the patient. The presence of substance abuse altered many students' views on confidentiality. In this experience students were less rigorous in their application of principles, creating an excellent opportunity for teaching through exploration of the complexity of ethical decision-making in a specific case.
\end{abstract}

\section{Introduction}

Many methods have been proposed to teach clinical ethics but little information exists on the effectiveness of these methods. Teachers may assume that class discussions lead to increased knowledge of ethical issues and to changes in behaviour, but few data exist to support or refute this view. Similarly, little is known about how students apply learned principles to their own behaviour. To evaluate the effectiveness of an ethics course based in a third-year medical school clinical ward rotation, Seigler and colleagues (1), developed case studies. The cases ended in a clinical question that the students were asked to answer; they were also asked to give reasons to support their answers. Scoring was based on both the number and the quality of their reasons. Students who had had the ethics course provided more but not 'better' reasons for their actions than students who had not had the course. Using a similar method, the

\section{Key words}

Medical ethics; confidentiality; substance abuse; health care; case studies. present study describes and evaluates the response of $\stackrel{0}{\circ}$ students to a specific case example presented as part? of an ethics course.

\section{Methods}

A multidisciplinary course in medical ethics taught by a faculty ethicist (TRM) is offered each year by ${ }^{D}$ the Department of Medical History and Ethics at the $\stackrel{\oplus}{\varnothing}$ University of Washington School of Medicine. The $\$$ class meets weekly for three hours in the evening for 10 sessions and focuses on such topics as truth telling, confidentiality, informed consent, resource $\bar{O}$ allocation and patient autonomy. For the last ten years, after students have been exposed to ethical $\stackrel{\perp}{\perp}$ theory and basic principles, including the vocabulary $\overrightarrow{\vec{F}}$ of medical ethics, one session has focused on ethical problems that commonly arise in primary care. A single case was selected for a written exercise in 1987? and 1988, using the same case both years, to increase the number of students studied. The case was presented orally and students were asked to $\overline{3}$ write down the ethical issues they felt were involved $\stackrel{3}{.}$. and what resolution they would recommend. Theo discussion following focused first on gathering additional information from the physician instructor 윽 on the specifics of the case and then on elucidating $>$ and debating ethical dilemmas and possible resolutions. Following the discussion, the students were again asked to record any new ethical issues they felt were involved and, again, what resolution 0 they would recommend. No attempt was made to $\mathbb{N}$ evaluate individual students but rather the method of instruction. Their anonymous responses wereo collected before and after the discussion. Theirळ mother's maiden name was used as an identifier to ${ }^{+}$ connect an individual's responses before and after the discussion. Students were also asked to provide $\frac{\vec{d}}{\mathbb{D}}$ their age, their discipline and how long they had $\stackrel{\odot}{\oplus}$

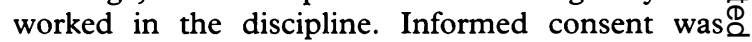
obtained from the students for participation and they were assured that the course instructor would 8 have no access to any of their responses until aftero the course was over and grades submitted.

The following case was presented by the physician instructor (NGS) from her own practice: 


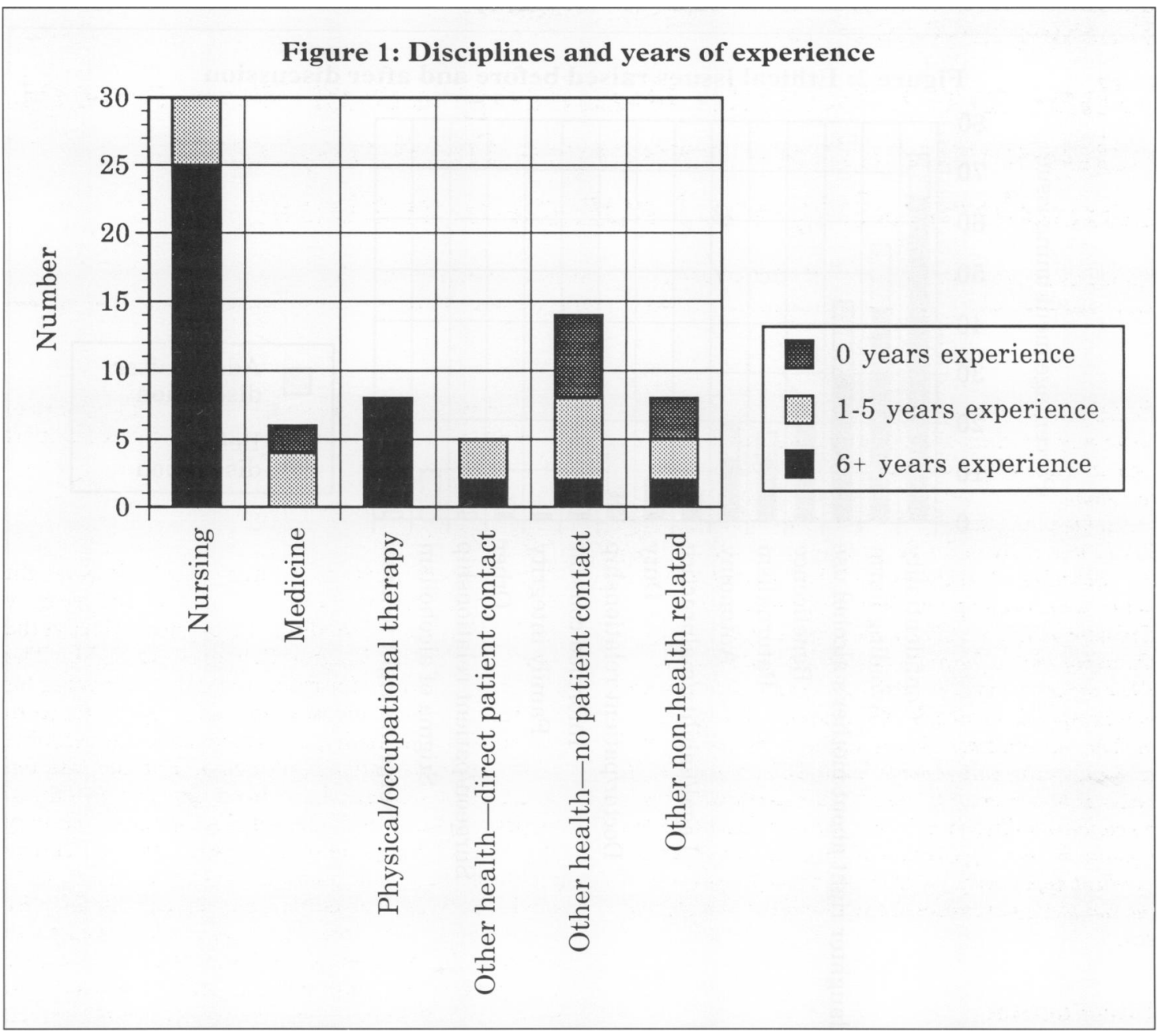

A mother and daughter are both my patients in a family practice. The mother is $\mathbf{4 2}$ and the daughter 19. The daughter comes to me partly on the advice of her mother, requesting disulfiram to help her stop drinking. The daughter confides in me that her mother also has a drinking problem but emphasizes that her mother told her not to tell me this and that I must under no circumstances let the mother know the daughter told me. Later the mother comes in to see me about another problem. In response to a question about alcohol consumption she reports she has one glass of wine with dinner and otherwise avoids alcohol because of her 'bad stomach'. On subsequent visits she continues to deny any problem with alcohol. The mother needs surgery and wishes to be referred to an outside surgeon. The surgery will involve a general anaesthetic and a five-day hospitalization. Alcohol dependence could be a risk for anaesthesia and it is possible she could get into difficulties with withdrawal over her hospital stay. What should I tell the surgeon?
The students' open-ended responses, listing ethical issues and possible resolutions, were analyzed as follows. First, a list of issues and resolutions was generated from a review of a sample of their responses. Second, two independent reviewers coded each student's responses, using a set of written coding guidelines, blinded to the analysis of the other reviewer. A third reviewer examined the responses where the first two reviewers disagreed. These cases involved distinctions such as the physician's obligation to 'avoid harm' versus 'to do good' (beneficence). The division of open-ended responses into categories was straightforward using the guidelines, with excellent agreement between reviewers.

\section{Results}

The ages of the 72 students ranged from 21 to 59 . Class members represented a wide variety of health and non-health related disciplines (Figure 1). In addition to medicine, nursing, occupational and 
114 Teaching medical ethics: What are students thinking when we present ethics cases?: an example focusing on confidentiality and substance abuse

Figure 2: Ethical issues raised before and after discussion

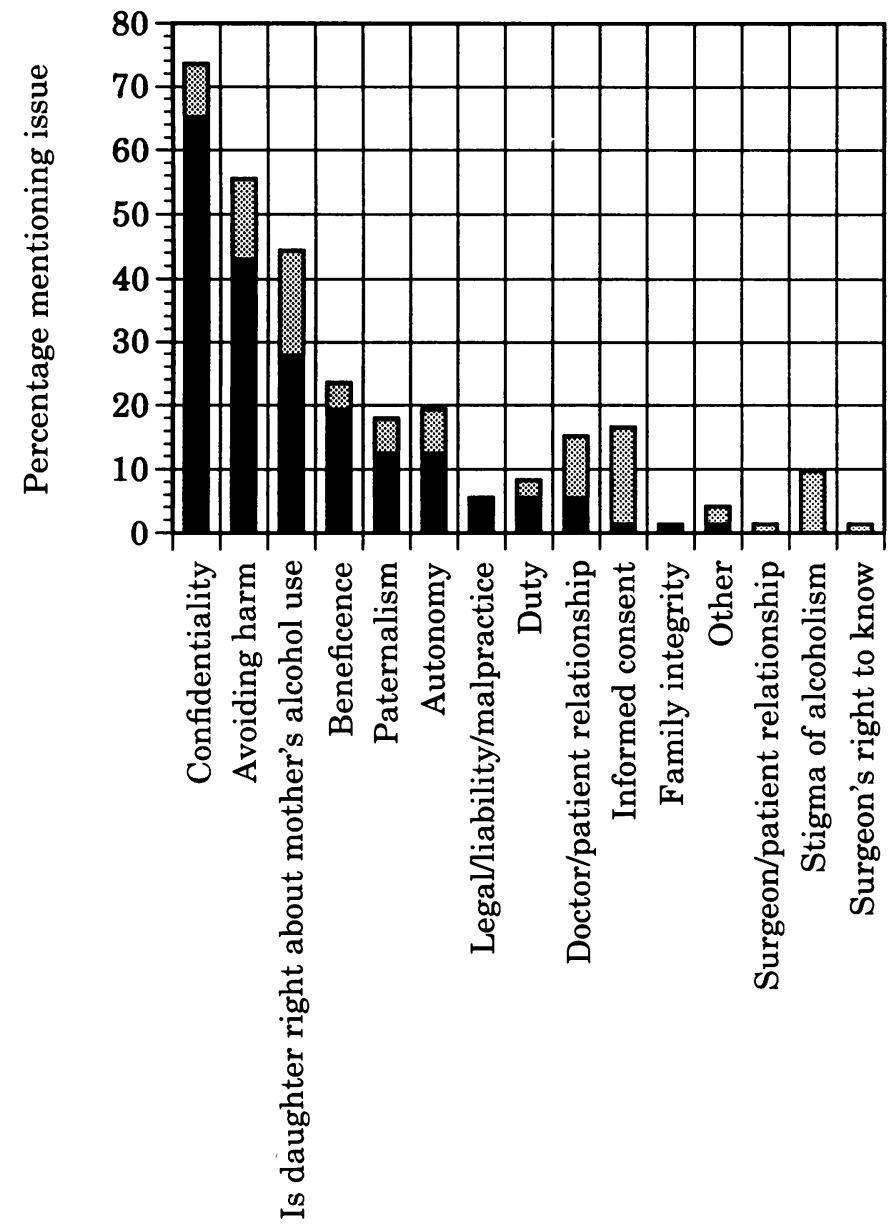

Added after

discussion

Before

discussion

physical therapy, other health-related disciplines were divided into patient contact disciplines such as pharmacy, speech pathology, and social work; and those with no patient contact such as health administration and public health. Non-health related disciplines included areas such as art, biology, and engineering. Experience ranged from 0 years (students in a discipline with no experience in the discipline) to over 25 years.

The ethical issues identified by class members are listed in Figure 2 along with the percentage of students mentioning that issue before the class discussion and those adding the issue after the discussion. Only issues made explicit by the writer were included. In other words if the reviewer could see an issue in what the student wrote but the student didn't identify it, it was not counted. Phrases such as 'be safe', 'be cautious', or 'avoid possible risks' were included in the 'avoid harm' category. Phrases such as 'patient's best interest', or 'protecting the patient' were counted as 'beneficence'. Comments about the patient's 'right $>$ to deny' were classified as an issue of 'autonomy'. A을. frequently raised issue was whether the daughter's $N$ information about her mother's alcohol abuse was accurate, shown here as is daughter right about 0 Mom's alcohol use?' Students listed an average of ${ }^{N}$ 2.4 issues before and 3.6 issues after the discussion. Students were asked what action they would takeco in this case. Figure 3a-c shows responses before and after class discussion. Only explicitly stated plans are ${ }^{+}$ counted in each category. Unless the student $\frac{T}{0}$ restated his or her original response or made $\mathrm{a} \underset{\mathbb{D}}{\stackrel{O}{O}}$ statement such as 'I would do the same thing', we $\stackrel{?}{?}$ did not count before discussion resolutions in the $\varrho$ after discussion category. The fact that the number of students suggesting each resolution drops fromo before to after the discussion may be a result of thiso limitation of the open-ended responses.

The first group of responses relate to informing the surgeon or hospital staff of the mother's alleged alcohol problem (Table 3a). Three response 


\section{Figure 3: How should issue be resolved?}

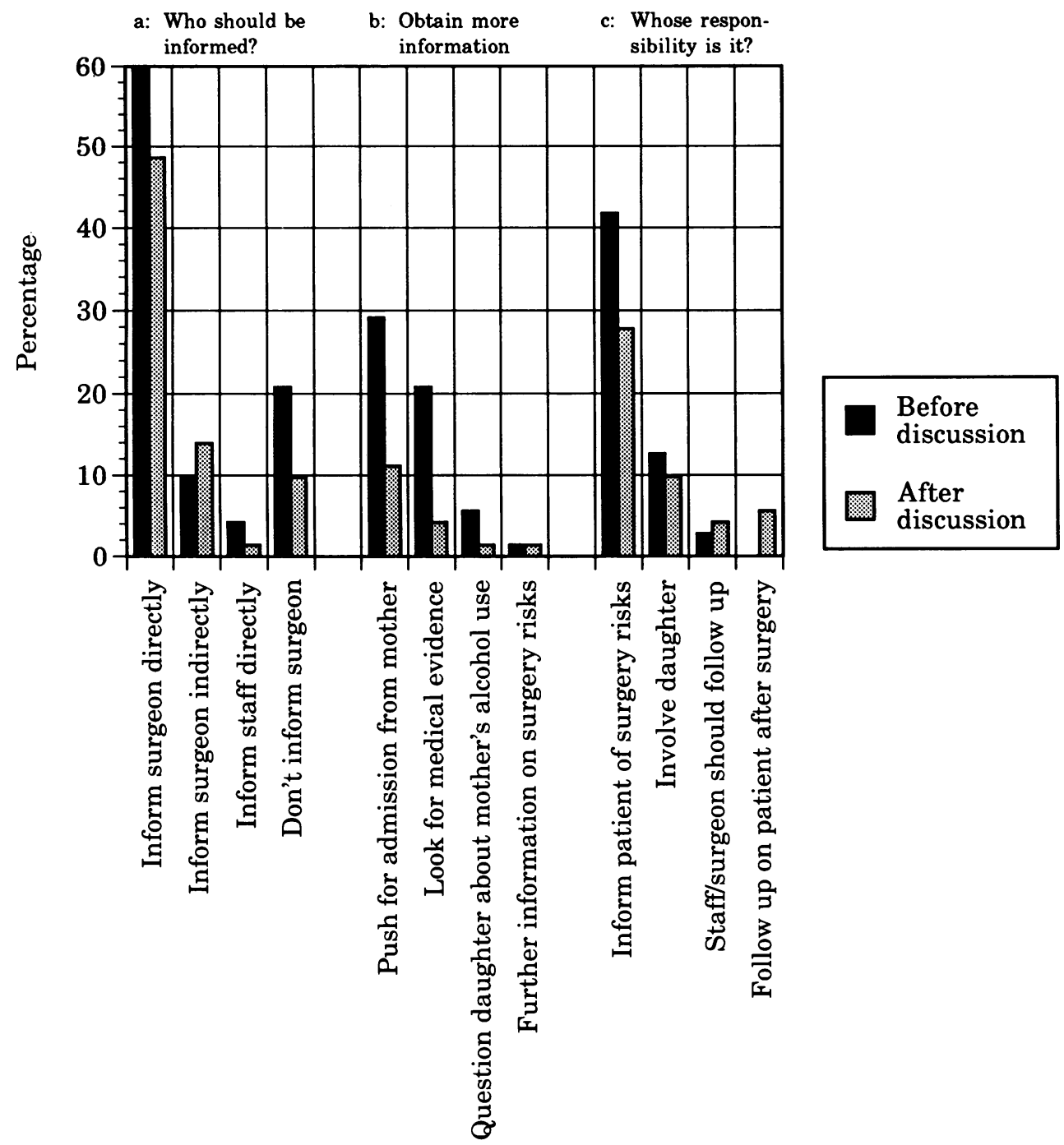

categories favoured methods of communicating the concern to the surgeon: 1) telling the surgeon directly what the daughter had told the family physician; 2) making indirect reference to alcoholism in the family in the chart or to the surgeon, and 3) informing hospital staff directly. The fourth response was a specific statement that the student would not inform the surgeon.

The next four categories (Table $3 b$ ) involve students' desire for further information about the case. They wanted more information on the risks of the surgery and more information from the daughter about the mother's drinking. They wished to question further the mother herself on the issue of her drinking and wondered if medical tests would help resolve the issue of her alcohol use.
Finally, many students identified the person who they felt was responsible for taking action on this issue (Table 3c). Suggestions included that the patient herself should be informed of the risks of alcohol abuse with her surgery so she could make appropriate decisions on her own; that the family physician should follow the patient personally to watch for alcohol-related problems; that it was the surgeon and hospital staff's responsibility to follow the patient for alcohol-related problems, regardless of information from other sources; and that the daughter should be involved to confront her mother, or to tell the surgeon what she had told the family physician.

After the class discussion 50 per cent (36/72) of students made explicit changes in what they would 
Teaching medical ethics: What are students thinking when we present ethics cases?: an example focusing on confidentiality and substance abuse

recommend or do in this case. Of those changes 36 per cent $(13 / 36)$ were changes in whether they would inform the surgeon or not. In reviewing student responses an unexpected additional theme emerged. Before the discussion 28 per cent (20/72) of the students explicitly wrote that it was acceptable to breach the daughter's confidentiality as long as neither the daughter nor the mother found out about it. After the discussion 18 per cent (13/72) still wrote that it was acceptable to breach confidentiality if the breach was not discovered.

\section{Discussion}

Our method of discussing specific cases from the physician instructor's practice allows a much more comprehensive look at the complexities of real cases. This proved a valuable method of engaging students in thinking about their own ethical behaviour. While students may endorse the importance of each of the ethical principles raised, when presented with a specific case they discover the complexities of applying these principles and the way their own beliefs and values interact to influence their behaviour. The class discussion was lively and at times heated. Students interacted freely and were willing to point out each other's ethical inconsistencies.

The data we report are necessarily limited to what students were willing or able to put in writing. Because we only recorded issues or resolutions specifically mentioned by a student it's likely that we have underestimated those considered. Many students tried to avoid the ethical conflict by requesting more information, hoping to get direct evidence of alcohol abuse or some other information that would eliminate or minimize the ethical issue. The instructor's knowledge of the particulars of the case allowed her to emphasize them during the discussion and to re-direct students to the conflict as presented, and to the need to resolve the ethical issues.

Several specific ethical concerns deserve comment. Despite mentioning confidentiality as an issue, the majority of students said they would inform the surgeon of the mother's alcoholism. This action was viewed as a breach of confidentiality by some. Others held that in telling the surgeon about the mother's alleged alcoholism the family doctor was not breaching the daughter's confidence but simply enlarging the scope of 'informed' caregivers, as is commonly the case in a team approach to patient care. Since this particular surgeon was unknown to the family doctor, it would have required a high level of trust in an unknown colleague to presume that the confidence would be rigorously guarded by the surgeon and his staff. Still others wondered about the mother's right to privacy since if she had a drinking problem, she had chosen not to disclose this information to her primary care physician.
After the discussion several students decided the surgeon should not be informed after all. However, $\overrightarrow{\vec{s}}$ several others changed in the opposite direction. $\frac{7}{0}$ Most of the students felt avoiding harm was a greater good than protecting confidentiality. As Bergsma (2) $\frac{\bar{m}}{\mathrm{~m}}$ has pointed out, health care professionals tend to $\widetilde{\mathbb{D}}$ have a high degree of 'medical positivism' or a kind of paternalism in which the professional's $s$ greater knowledge of, or belief in, the efficacy of $\vec{\circ}$ treatment is seen as a reason for overriding $\overrightarrow{\vec{\omega}}$ the patient's autonomy. This may explain these $\stackrel{\omega}{\sigma}$ students' responses. Culver and colleagues (3)

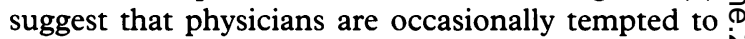
breach confidentiality. Our results suggest that this 0 temptation may be common. Of particular interest is ? the number of students who felt it was acceptable to $\overrightarrow{\vec{N}}$ tell the surgeon as long as the patient and her daughter never found out.

Students expressed their beliefs about where the $\vec{c}$ responsibility to avoid harm lay. The majority felt the patient should be informed of potential risk and it was her responsibility to act appropriately. Several $\vec{c}$ felt it was the daughter's responsibility to confront $\nsubseteq$ the mother. Very few students suggested it was the surgeon's responsibility to be alert to potential alcohol problems in this or any other patient. In fact, in addition to avoiding harm to the patient, several students suggested the surgeon had a 'right to know' $\mathbb{D}$ about the patient's possible alcoholism to protect $\overrightarrow{\vec{B}}$ $\mathrm{him} /$ herself from mistakes. One sensed that students may have identified more with the health care providers than with the patient, an interesting finding, especially in a class with a large number of graduate student nurses who might have been expected to identify more with the patient than the physician.

Alcoholism and its treatment emerged as an issue that divided the class in several ways. Some students felt the stigma of alcoholism increased the patient's 을 need for confidentiality. They felt that: 1) the patient had a right to deny it and 2) the daughter's story might not be correct. Others felt that confronting the $\bar{N}$ mother directly about her alleged alcohol abuse was the only effective treatment and therefore overrode $N$ her right or her daughter's right to confidentiality or $\mathbb{\omega}^{N}$ autonomy. These students suggested that the family $\sigma$ doctor and the daughter organize a classic substance 6 abuse 'intervention' with the mother to confront her $\mathbb{D}$ alcoholism and get her into treatment. Although this $\stackrel{?}{+}$ technique is widely used in the initial stage of $\square$ substance abuse treatment, we believe that under the circumstances the physician should not be a party to $\cong$ the intervention. To be a party to such an $\stackrel{\mathbb{Q}}{\Omega}$ intervention would entail treatment for an alleged $\bar{\sigma}$ problem without patient consent. In addition, if the physician had any evidence to support the diagnosis $\frac{0}{0}$ of alcoholism, which had been learned directly from the mother, the physician's involvement in the intervention would entail a breach of patient confidentiality. No student identified the breach of 
the mother's confidentiality which would result if the daughter was told of the mother's impending surgery or medical condition.

Ethical principles and their application were emphasized in this class. Through case discussion students learn to avoid the temptation to treat such principles as rules which are to be followed literally without regard for context. A recent example from the literature illustrates this well. Patterson et al describe cases in which a patient who has recently suffered a complete spinal cord injury asks for the termination of life support while still undergoing intensive care (4). A high regard for patient autonomy ordinarily requires respect for the patient's decision to discontinue medical treatment. Although legally competent, the patient's 'capacity' to make a decision in the service of his best interests may be seriously compromised or diminished by the features of the situation. In such cases the patient should be encouraged to undergo stabilization and treatment while gathering information about long-term rehabilitation. Discussion of such exceptions leads students into a deeper appreciation for the richness and complexity of individual cases, which must be thoroughly considered in working through an ethical analysis toward a justifiable recommendation.

We suspect that in exploring an issue such as privacy and confidentiality, the use of an everyday example like ours led to the emergence of more accurate reflections of the students' likely behaviour. Even though in a more dramatic classroom example students may identify confidentiality as an important principle, they may in the complexities of everyday practice breach it regularly through some sense of higher 'good' or the sense that it matters little as long as the patient fails to discover the breach. Discussion in the class gave the faculty and fellow students opportunities to point out the application of principles and to explore when exceptions to the principles ought reasonably to be made. It is just these kinds of distinctions we need to engage students in examining if we are truly to affect their behaviour.

The study raises some intriguing questions about ethical behaviour. How is confidentiality actually honoured in practice? How often are confidences betrayed when the chance of discovery is low? Does a patient who is abusing alcohol or suspected of doing so have different rights to privacy and confidentiality from one who is not? What should the patient's physician's role be in interventions designed to coerce the patient into substance abuse treatment? Is it easier to relate to another provider's need to know, in order to prevent a potential mishap, than to a patient's need for privacy when that need seems misguided to the health care provider? Discussion in the class and written responses revealed widely disparate views on each of these issues. Each merits further study.

Nancy G Stevens, MD, MPH, is Associate Professor in the Department of Family Medicine, and Thomas $R$ McCormick, D Min, is Senior Lecturer in the Department of Medical History and Ethics, both at the University of Washington School of Medicine, Seattle, Washington.

\section{References}

(1) Seigler M, Rezler A G, Connell K J. Using simulated case studies to evaluate a clinical ethics course for junior students. Fournal of medical education 1982; 57: 380-385.

(2) Bergsma J, Thomasma D C. The contribution of ethics and psychology to medicine. Social science and medicine 1985; 20: 745-752.

(3) Culver C M, Clouser K D, Gert B, et al. Basic curricular goals in medical ethics. New England journal of medicine 1985; 312: 253-256.

(4) Patterson D, Miller-Perrin C, McCormick T, Hudson L. When life support is questioned early in the care of patients with cervical-level quadriplegia. New England journal of medicine 1993; 328: 506-509.

\section{News and notes}

\section{'Advance directives are binding'}

According to the leading article in the January newsletter of the Voluntary Euthanasia Society, advance directives are binding. The piece quotes the case of $\mathrm{C}$, a patient in Broadmoor Special Hospital, who won a high court injunction to stop doctors either then or in the future amputating his gangrenous right leg. Doctors were ordered by the court 'to respect C's wishes even if in future he becomes incapable of making decisions'.

C's current refusal was only spoken, says the article, he did not have a written advance directive. 